likely that the phenomenon of structure arises from some as yet unknown peculiarity of collagen. The details of structure depend more on the nature and stereochemistry of the interacting molecules.

In concluding this account it is a pleasure to pay tribute to the enthusiastic efforts of the colleagues whose work I have largely described, and the invaluable support of the technical staff of the laboratory.

\section{TREE GROWTH ON ACID SOIL}

A JOINT session of Sections $K$ (Botany) and $K^{*}$ (Forestry) of the British Association devoted the whole day at Oxford on September 7 to a symposium on "The Interactions between Acid Soils and Forest Trees". Biologists whose joint research interests covered a wide variety of subjects combined with practical foresters in an attempt to solve, or at least to restate in simpler terms, the problems of establishment and maintenance of forests on heathy and peaty soils.

Mr. M. V. Laurie, chief research officer of the Forestry Commission, opened the discussion by presenting the forester's point of view, based upon the thirty-five years experience of the Cornmission. $\mathrm{H} \theta$ pointed out that much of the land at present available for reafforestation in Britain is acid and that two classes of problems therefore exist. First, the problems concerned with the effects of acid soil on the establishment and growth of trees ; and secondly, those concerned with the effects of the trees themselves upon soil fertility. Soil is the working capital of the forester and he has therefore a duty of maintaining it, undiminished in productivity; in perpetuity while producing the right crop of the highest quality.

On the land available, the solution of the problems of tree establishment consumed much of the early effort of the Commission. Preliminary treatments such as ploughing, draining and the application of fertilizers are effective on many sites; but the degree to which they are valuable and the magnitude of the improvement in tree establishment that they produce are not easily predictable. The full interpretation of the results of early successes and failures demands not only long-term experiments on a large scale but also the co-operation of experts. The effectiveness of mixtures of Sitka spruce and Japanese larch or pine, the beneficial effects of broom on spruce growth and the universally adverse effect of heather on all tree species must be interpreted by ecological experimentation. The stimulation of many species by phosphate on sites where lime and nitrogenous fertilizers are ineffective requires the co-operation of physiologists and microbiologists for explanation. Microbiologists, too, must assist in helping to determine the rival claims of organic manures and composts as against balanced applications of artificials. All these problems concerned with forest establishment are in the process of being solved with the help of specialists, but the long-term question of fundamental importance-the effect of trees on the soil-remains.

The vigorous forests of young conifers which have been established are undoubtedly changing the soil. In the place of the much modified heath soils, acid woodland mor with a deep layer of needles is being produced. It is held by many ecologists that mor conditions lead to serious soil degeneration. Two points must be considered in this regard. First and foremost, the demand for timber is mainly a demand for pine and spruce. A supply of poor-quality hardwood, even if such a crop prevented mor formation, would not be economic. Secondly, it would seem that what we believe to be natural northern coniferous forest exists almost exclusively on mor or podsolized soils as a self-regenerating natural forest.

Dr. G. W. Dimbleby, of the Department of Forestry, Oxford, was opposed to the view that mor conditions should be allowed to develop in newly established forests. $\mathrm{He}$ stated that podsol and its attendant raw humus layer form an undesirable medium for the growth of forest in Britain and it is, moreover, avoidable. Dr. Dimbleby described the work of a research team in Oxford which had undertaken fundamental research on many aspects of tree nutrition. The team concentrated its attention on areas in Yorkshire, where tree establishment on high-level heather moors is beset with great difficulty. It has often been stated that these moors are a natural ecological climax. This view has been shown to be erroneous by the study of the soil surfaces and profiles beneath bronze-age earthworks. On the surface below these artificial mounds, charcoal of birch and oak is found on the sites of hearths. The soil surface is rich in the pollen of hazel, oak, lime and alder and lacking in heather pollen. The soil profile below is typical of a brown forest mull. Indeed, the podsol profile of the heath goes over the top of the earthworks and is undoubtedly of more recent development. The vegetation and the soil have undergone a change from mixed deciduous forest on brown earth to heath on podsol since bronze-age times, and evidence suggests that man's activity in cutting, burning and grazing is the cause. Nowadays, when burning and grazing are prevented, birch and pine may seed themselves into the heaths. Of these, birch becomes established, its roots break through the iron-pan of the podsol and its leaf litter and the detritus from associated plants convert heather mor to mild humus so that a forest soil with a vigorous fauna becomes established. Pine, on the other hand, fails to break the pan, and the mor conditions and bad drainage are exaggerated, and acidity and poor nutrient status are maintained.

The effects of birch in this sequence are essentially similar to the effects of soil treatment. Ploughing causes breakage of the pan and improves drainage and aeration. Mulching and manuring temporarily simulate the beneficial nutritional status of mull. If pine is planted this improvement is reversed; and leaching and podsolization develop with the accumulation of deep needle litter in which vast stores of minerals, which would otherwise be available, are locked.

The beneficial effects of birch and other species under which brown earth develops can probably be partly interpreted in terms of the behaviour of their litter during breakdown. The cellulose in the walls of the mesophyll of heather and mor-producing species is protected from breakdown by a resistant layer of a tannin-protein complex which is laid down upon them as they die. This is usually lacking in species not producing mor and, indeed, admixtures of birch litter or extracts of it can be used to stimulate breakdown of mor.

Prof. L. G. Romell, of Sweden, who was guest speaker, discussed the formation of mor. He pointed. out that the humus turnover in mull soils is not faster than that in mor, and indeed the amount of organic matter is often higher in them. Moreover, when mor is isolated and stored, loss of organic 
matter and release of available nitrogen occur. The form of the curves relating these changes with time of storage is such as would be expected when a material high in nitrogen content is available for decomposition. The application of lime to decom. posing mor in storage increases the rate of loss of organic matter but decreases the rate of release of available nitrogen. The immobilization of nitrogen in the presence of lime is due in part to reaction of ammonis with quinoid complexes in the humic matter.

The examination of a mor profile shows it to be characterized by a great concentration of roots, mycorrhizas and mycelia. Acidity is not, however, a diagnostic character of mor because mull may have a similar $p H$ range. In beech soils, mor develops inevitably as the forest ages, so that liming and forest treatment cannot arrest the change from mull to mor. In the time of P. E. Müller (who first used the terms 'mor' and 'mull' in their present sense) mor wos widespread in Denmark; now it is rare. The old beech stands are gone, and in the young forests mull exists in its stead. Similar parallelisms between mor development and the age of stands are found throughout the spruce forests of Sweden.

The factors affecting the development of mor have been analysed by ecological experiment. Addition of nitrogenous manures causes stimulation of ground flora and tree growth on mor soil. Other fertilizers have little effect. The death of trees from natural causes or felling is followed by a quick response, and dense ground flora develops. Trenching experiments where roots are cut have similar effects, producing dense ground flora, high nitrogen and phosphorus content of vegetation and the disappearance of the mor profile. All these experiments, taken in conjunction with estimates of the release of available nitrogen during storage, indicate that the prime factor in mor formation is nitrogen starvation. The intensification of competition for nitrogen by roots and mycelia as a stand ages leads to formation of mor, decrease of ground vegetation and slow growth of trees. Such $\mathrm{a}$ view of the mechanism of formation of mor, although it runs counter to many accepted teachings, explains more closely the ecological and experimental data.

The wide experience of Prof. Romell and the intensive researches of the soil nutritional team described by Dr. Dimbleby seemed, therefore, in full agreement concerning the relative productivity of mor and mull and the need to prevent development of mor. Suitable sylvicultural measures could prevent its development, and these were dealt with in subsequent discussion.

Dr. S. D. Garrett described work done at the Botany School, Cambridge, on the microbiology of acid soils with respect to soil-borne disease. He took two examples where there is an apparent correlation between $p \mathrm{H}$ and intensity of disease. Both in the case of Fomes annosus butt-rot of pines and spruces and in Pythium disease of seedling roots, disease is less intense in acid than in alkaline soils. The diminution of the damage caused by Fomes on acid soils can be ascribed to an effect of $p \mathrm{H}$ upon the soil micro-flora rather than upon the pathogen or host. Fomes spreads inside and along the surfaces of living roots and passes from host to host by root contact. Rapid advance along the root-surface, leading to widespread disease, is possible on alkaline soils, because Trichoderma viride, a virulent antagonist of Fomes, is absent. On acid soil only an internal spread of Fomes is possible, and the disease is of less importance. Pythium diseases of seedling conifers are alsc less intense on acid soils and in this respect they contrast with similar diseases of crucifers. The effect of $p \mathrm{H}$ may here be ascribed to a direct effect on the host and not upon the pathogen. The ecological optimum of conifers lies on the acid side of neutrality, so that they resist the disease on acid soils.

Although these examples illustrating the causes of increase or decrease of virulence with soil conditions appear simple when the final conclusions are reached, they are based upon wide ecological surveys in which apparent correlations, many of them spuriously giving the impression of causation, are observed. Such observations must be followed by detailed controlled plot and laboratory experiments.

Dr. J. L. Harley, of the Depertment of Botany, Oxford, also discussed soil microbiology in an attempt to fit work on the physiology of mycorrhiza done in Oxford into its ecological perspective. The concentration of roots and mycelia in the mor profile described by Prof. Romell is easily observ. able in beechwoods in Britain. Estimates of weights of absorbing roots in various horizons of mull and mor confirm the intense colonization of the $F$ and $H$ layers of the latter. These roots are mainly mycorrhizas and are completely clothed in a tissue of fungus through which all nutrients entering the tree must pass. Observations on spruces by Wilde in America and on beech in Oxford show that similar subsurface aggregation of roots can be induced by treating even highly nutritive soils with excessive surface layers of organic material. Following the aggregation of roots, starvation symptoms can develop. The conditions in which mycorrhizal roots show their greatest development are these conditions of intense competition for nutrients. It is possible with beech, as has been shown in Sweden and America for pine and spruce, to vary the intensity of mycorrhizal infection by arranging a deficient supply of nutrients in the soil while ensuring rapid photosynthesis and carbohydrate production. The ecological conditions of intense mycorrhizal formation are those in which growth-rate may be small. Indeed, an inverse correlation of growth and mycorrhizal infection is often observed in natural conditions. Such correlations provide no evidence concerning the functioning of mycorrhizal organs, which must be sought in laboratory experiments.

If conventional physiological methods of studying nutrient absorption by roots are applied to mycorrhizal roots, it is readily shown that they accumulate salts in their tissues. The rates of accumulation of phosphate, ammonia and the alkali metals are rapid, and the mechanism of absorption is linked with metabolic activity. The rate is very sensitive to temperature, oxygen supply and the presence of metabolic poisons. It is very rapid in oxygen concentrations approximating to that in air and, in some conditions, is closely correlated with oxygen consumption in respiration. Comparisons of the rate of absorption of minerals by mycorrhizal and nonmycorrhizal roots of beech and pine show greater rates of accumulation into mycorrhizas of all salts tested. The mycorrhizas may therefore compete on more level terms than uninfected roots with the mycelia and other roots in the soil. The primary destination of the salts absorbed is into the fungus, and phosphate in particular accumulates in the fungel layer at first, so that during absorption the supply 
of phosphate to the host tissue is no greater in mycorrhizal than non-mycorrhizal roots.

Two mechanisms have been studied by which the ions trapped by the mycorrhizal sheath of fungus can be made available to the host. First, it has been shown by direct observation and photographic record that beech mycorrhizas have a life-period of about eight months only. Hence there is a periodic release of mineral-rich organic matter into the actual rooting region of the host. Secondly, there is in the tissues a metabolic turnover of phosphate, sensitive to oxygen and temperature, the net result of which is the movement of phosphate from fungus to host during periods when the rate of uptake is low. Hence, during periods of rapid release of minerals from newly fallen litter, nutrients may be trapped and accumulated in the fungal layer of mycorrhizal roots and, in the subsequent periods of slower mineral release, phosphate and perhaps other minerals are passed to the host. Laboratory physiological experiments, therefore, are providing a credible picture of the functioning of mycorrhizas in ecological conditions.

Dr. L. Leyton, of the Oxford Forestry Department, described detailed work on mineral nutrition of conifers which has been carried out in the same areas as that described by Dr. Dimbleby. His description of the soil profiles of sitka spruce forest in Yorkshire was exactly comparable with that of previous speakers, and his analysis of mor and mull again emphasized the deficiencies of available soil nutrients, especially of nitrogen. Significant increases of growth were obtained by the application of nitrogenous manures, and little increase was obtained with phosphate. Dr. Leyton described the technique of analysis of foliage to determine the nutrient status and mineral deficiencies of the site. On untreated soils, needle weight and nitrogen content are positively correlated, and the effects of the use of nitrogen fertilizers, removal of heather and mulching owe their efficacy in promotion of grewth to increase of available nitrogen. Application of phosphate only affords a secondary stimulation.

The humus layer contains as much as 2 per cent of dry weight as nitrogen, so reasons were sought as to why this is not made available. Calcium deficiency is very marked, and it is possible that microbiological activity is limited by this factor. On the other hand, the soils in question are often water-logged in winter and dried out in summer. This adverse water rógime may be counteracted by mulching, which results in a rapid increase of microbiological activity in the rooting layer.

The method of needle analysis has proved very valuable in this study, for it can be used to predict as well as to follow the effects of soil treatments on trees of any size. In all cases where treatments improve growth, an immediate response in needle colour and weight preceeds increased growth. The needles of the following year's crop are laid down in the buds of the current year, so that although immediate growth response to treatment is not observable, the constitution of the needles provides a satisfactory basis of prediction of growth in the future.

With these set papers as a background, the whole subject was discussed. Prof. Romell pointed out that the effects of liming are complicated because of the stimulation of white rot fungi above $p \mathrm{H} 4 \cdot 5$, and the lack of effect of lime treatments mentioned by $\mathrm{Mr}$. Laurie and others might be explained by the trapping of nutrients by them. He asked about the stimulation of turnover in mor by hardwood litter, and Dr. Dimbleby and Mr. Murphy stated that it can occur and is associated with increase of faunal activity. Dr. Dimbleby spoke strongly in favour of developing stands of mixed tree species, but Mr. Hiley emphasized that adequate thinning of conifers would encourage ground flora, the detritus of which would have the required effect of reversing the tendency to formation of mor. $\mathrm{H}_{\theta}$ also described how mor develops under old oak stands and how felling of such stands and replanting with conifers may give rise to mull with an Oxalis and Rubus ground-flora. Dr. Harley pointed out that such a change might be the result of felling and planting rather than an effect of the conifers themselves. Mr. Laurie showed that there are still untouched problems concerning the factors leading to the aggregation of roots so characteristic of mor. He asked if some of the known effects of mycorrhizal and other fungi on the growth and branching of roots could be a factor in the process. Dr. Harley and Dr. Leyton suggested that a study of oxygen supply and water supply in the surface soil layers would perhaps be a better first approach to these problems, as both these factors greatly affect root-growth and activity. Prof. W. H. Pearsall, who was in the chair, commented that although there was clearly evidence that many of those present disagreed on various grounds with the planting of conifers on many sites in Great Britain, no battle had developed on this subject. The first problem in reafforestation, he said, is to make difficult sites productive and then to ensure that their soil tends to change towards mull rather than away from it. Britain is a region of brown forest soils, and present policy should be to reestablish them. No doubt it was felt that such a discussion would lead the meeting away from biology into economics, for in spite of this challenge no battle developed.

The meeting was a highly successful discussion of a most important subject, and indeed was a hard but valuable day's work for those who took part.

\section{ANIMAL BEHAVIOUR}

$A$ $T$ the recent meeting of the British Association in Oxford, Sections D (Zoology) and J (Psychology) held a joint discussion on "Animal Behaviour", which was attended by some four hundred members. The discussion dealt with the study of animal behaviour as it is practised by Konrad Lorenz and other zoologists who follow his lead. These investigators usually refer to themselves as ethologists, and the first two papers presented some of the features of their method, some of their findings, and some of their theoretical concepts. The third paper was given by a psychologist, who considered some of the relations between ethology and psychology.

Dr. N. Tinbergen (Department of Zoology and Comparative Anatomy, University of Oxford) opened. the discussion with a paper on the bearing of the ethological study of animal behaviour on the study of human behaviour. He began by stressing the need for restraint in making comparisons between animals and men, and by saying that, in his view, the importance of Lorenz's work, and of ethology generally, lies not so much in any new theory of behaviour that has been put forward as in its particular type of approach. This approach sets great 